\title{
Ley sagrada y ley civil en los países árabes: el caso del delito de fornicación ilícita
}

\section{Holy law and civil law in Arab countries: the case of illegal sexual intercourse}

\author{
Juan Manuel URUBURU COLSA ${ }^{1}$ \\ Departamento de Filologías Integradas, Área de Estudios Árabes e Islámicos. \\ Universidad de Sevilla \\ uruburu@us.es
}

Recibido: mayo 2010

Aceptado: diciembre 2010

\section{RESUMEN:}

El delito de relaciones sexuales ilícitas, por su condición de delito coránico, ha estado históricamente presente en el Derecho de las sociedades árabes. Sin embargo, la profunda renovación que se producirá en el Derecho Penal de los países árabes durante la colonización ha dado lugar a una situación actual heterogénea. Por una parte, una serie de países han sustituido esta legislación tradicional por los modelos jurídicos europeos. Por otra parte, una serie de países árabes han optado, en un momento determinado de su historia, por sustituir esta legislación de tipo europeo por otra, que si bien es positiva y codificada, está inspirada en la jurisprudencia de las Escuelas Jurídicas clásicas. Esta divergencia es, en cierto modo, representativa de la dialéctica entre tradición, identidad y modernidad existente en el Derecho Penal de los países árabes.

Palabras clave: Derecho penal, relaciones sexuales, países árabes.

\begin{abstract}
:
The crime of unlawful sexual intercourse, because it is deemed a crime in the Qur'an, has existed throughout the history of criminal law in Arab societies. However, the comprehensive reformation that took place in criminal law in Arab countries during the period of European colonization has led to a very different situation. On the one hand, a some Arab countries have replaced traditional law with European legal models; on the other, a number of Arab countries opted, at a given moment in their history, to replace the European-type legislation for another that, while it is positive and codified, is based on the jurisprudence of the classical schools of law. To some extent, this divergence reflects the dialectic that is ongoing between tradition, identity and modernity in criminal law in Arab countries.

Key words: criminal law, sexual intercourse, Arabic countries.
\end{abstract}

ÍNDICE: I. Introducción, II. El delito de fornicación ilícita en la Šar̄̄a. III. El delito de fornicación ilícita (zinā) en el Derecho contemporáneo de los países árabes. Posturas. 1. Asimilación del delito de fornicación (zinā) a las categorías jurídico-penales de tradición europea. 1.1. Contexto Histórico. 1.2. El ámbito material del delito: De la fornicación ilícita al adulterio. 1.3. La diferenciación del tipo y de la pena por causa de género.1.4. La legitimidad

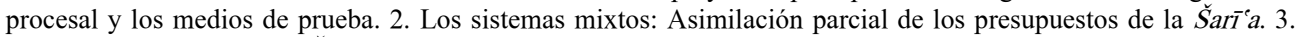
Legislación basada en la Šr̆̄̌a: Vías de adopción. 3.1. La reinstauración del Derecho Islámico clásico. 3.1.1. Contexto histórico. 3.1.2. El ámbito material del delito. 3.1.3. Los medios de prueba. 3.1.4. Las penas. 3.2. La continuidad en el Derecho islámico clásico. IV. Conclusiones.

\footnotetext{
${ }^{1}$ Doctor en Derecho. Investigador "Programa Ramón y Cajal". Área de Estudios Árabes e Islámicos. Universidad de Sevilla
} 


\section{INTRODUCCIÓN}

En cuanto parte esencial de las relaciones sociales y de las estructuras familiares, las relaciones sexuales, han constituido, desde tiempos remotos, una cuestión relevante para el Derecho en la mayoría de las civilizaciones. En el caso de civilizaciones, como la islámica, que han construido los cimientos de su Derecho a partir de prescripciones religiosas, la regulación de las relaciones sexuales adquiere una importancia especialmente significativa.

Esta cuestión ha mantenido su relevancia jurídica hasta nuestros días en los países árabes estableciendo una brecha cada vez mayor con respecto a la postura seguida por el Derecho en la mayoría de los países europeos. Efectivamente, mientras que para el legislador europeo la conducta sexual del individuo es jurídicamente irrelevante, siempre que no entre en conflicto con otros derechos constitucionales, para el legislador en los países árabes el ejercicio de la libertad sexual está sujeto a una serie de condiciones más estrictas que varían de un país a otro.

Obviamente, el punto de partida para explicar las actuales convergencias y divergencias entre los países árabes con respecto a esta cuestión se ha de encontrar en la propia evolución del Derecho Penal de estos países hasta su estado actual. Sin embargo recurrir apenas a la tradición jurídica de los siglos áureos de la civilización islámica, como se ha intentado en ocasiones, sería una vía muy limitada para explicar esta cuestión. El estado actual del Derecho en los países árabes no se puede entender en su globalidad sin tener en cuenta una cuestión fundamental como es el contacto con las tradiciones jurídicas occidentales iniciadas durante el periodo colonial.

Esta penetración colonial de occidente en el mundo árabe, iniciada a partir de la expedición napoleónica a Egipto en 1798, trajo a estos territorios nuevas necesidades sociales y realidades jurídicas a las que era preciso dar una respuesta normativa. En una primera fase se extenderá un sentimiento general de que el derecho islámico era incapaz de dar respuestas a los nuevos retos del siglo XX. Por ello, se buscó la respuesta en la importación de modelos legislativos occidentales en ámbitos tales como el Derecho penal, produciéndose una simbiosis entre los modelos jurídicos del Derecho islámico tradicional y los derechos de los países europeos. Sin embargo, esta simbiosis ha sido bruscamente alterada, debido a los diferentes movimientos de reacción contra la influencia política, cultural y jurídica occidental, en varios países árabes desde la década de los años 70 , lo que ha conducido a una heterogeneidad de posturas del legislador frente a cuestiones tales como las relaciones sexuales. Una heterogeneidad que, a nuestro entender, resulta representativa de las dificultades que entraña, en supuestos tales como el de las relaciones sexuales ilícitas, la simbiosis sobrevenida entre diferentes modelos jurídicos fruto de decisiones políticas que se encuadran en contextos más amplios que el de la propia evolución de los valores fundamentales de las sociedades.

Esta situación actual ha despertado nuestro interés en la realización de un estudio comparado de la legislación penal contemporánea de los países árabes sobre el delito de fornicación ilícita. Este estudio cuenta con dos objetivos básicos. Por una parte, y al mismo tiempo que analizamos los ejes fundamentales de estas 
legislaciones, nos proponemos contraponer su contenido con las fuentes en las que se inspiraron, mostrando de este modo un ejemplo especialmente interesante del pluralismo de sistemas jurídicos existente dentro del mundo árabe. Por otra parte nos proponemos confrontar esta legislación con el contexto histórico en el que surge esta normativa con el objeto de identificar los fundamentos de la política legislativa seguida por los países árabes ante la cuestión del delito de relaciones sexuales ilícitas. Para ello realizaremos una breve exposición de los elementos característicos de la regulación de este delito en los ordenamientos jurídicos que inspiraron el derecho de los países árabes, proponiendo una clasificación de estos países en atención a la postura adoptada por el legislador sobre esta cuestión.

\section{EL DELITO DE FORNICACIÓN ILÍCITA EN LA ŠAR $\bar{I} A$}

El delito de fornicación ilícita, denominado en árabe zināo zinā'ocupa un lugar central dentro del Derecho Penal de la Šarīa ya que pertenece a la restringida categoría de delitos cuyas penas ( $h a d d$, pl. $h u d u \bar{u} d)$ aparecen prescrita en el Corán y en la Sunna. Por ello, estos delitos tienen una naturaleza jurídica muy específica, ya que el bien jurídico protegido no son los derechos de los hombres ni del Estado sino la palabra divina. Esto provoca que, a la luz de la $\breve{S} a r \bar{\imath} a$ a, tanto el tipo penal como la pena prevista, sean inmutables y no susceptibles de perdón o de reducción por parte de la justicia de los hombres.

El tipo penal del delito de zinā ha sido definido por la doctrina clásica como "cualquier cópula (entre un hombre y una mujer) sin un contrato matrimonial válido, una presumible relación matrimonial o un concubinaje legal". ${ }^{2}$ De este modo, a pesar de existir ciertas diferencias en su formulación, la doctrina de las Escuelas jurídicas clásicas coinciden en exigir la concurrencia de dos circunstancias para la existencia del delito. La primera de ellas es la consumación de un acto sexual entre un hombre y una mujer, y la segunda es que ambos no estén vinculados, ni la realidad ni en la apariencia, por medio de un contrato matrimonial válido ${ }^{3}$. La pena por esta conducta aparece reflejada en el Corán y consistía en cien latigazos ${ }^{4}$. Sin embargo entre las diversas colecciones que conforman la Sunna se encuentran al menos tres hadices, atribuidos al Profeta Muhammad y al Califa ' $\mathrm{Umar}^{5}$, que servirán como base legal para aplicar la pena de muerte por lapidación en el caso de que el delito de zinā fuera cometido por una persona casada.

${ }^{2}$ IBN RUSHD: Bidāyat el-Mudjtahid, citado en SIDIAHMED, Abdel Salam,:"Problems in contemporany applications of Islamic criminal sanctions: the penalty for adultery in relation to women”, British Journal of Midle Eastern Studies, 28, 2 (2001), 187-204 p.

${ }^{3}$ MUQĀṬ, 'Imād: 'Ațar al-zurūf al-țāri'a 'alà ḥadd al-zinā fl-l-fíqh al-islāmī. Al-Ŷāmi'a alIslāmiyya - Gaza, Gaza, 2007, p. 4.

${ }^{4}$ Corán, 24, 2. "Flagelad a la fornicadora y al fornicador con cien azotes cada uno. Por respeto a la ley de Alá, no uséis de mansedumbre con ellos, si es que creéis en Alá y en el último Día. Y que un grupo de creyentes sea testigo de su castigo". CORTÉS, Julio, El Corán, Herder, Barcelona, 2005, p. 325.

${ }^{5}$ Cfr. PETERS, Rudolph, “Zinā or Zinā' ”, Encyclopeadia of Islam, Second Edition. Brill, 2005, p. 551-552 
La prueba de la existencia de este delito estaba sometida a exigentes requisitos. Básicamente son admitidos dos medios de prueba, la confesión judicial y la prueba testimonial ${ }^{6}$. Este testimonio debía ser realizado por, al menos, cuatro hombres ${ }^{7}$, musulmanes y dotados de reputación, que atestiguaran haber visto el acto de penetración "como un bastón de colirio penetra en su recipiente". En el caso de que su testimonio no fuera considerado verdadero estos testigos incurrían en un delito de falsa acusación ( $q a d f$ ) castigado con 80 latigazos. Por ello, ante la dificultad probatoria de este delito, la Šrī'a deja la puerta abierta al ta'zīr, es decir, a la capacidad discrecional sancionadora del juez cuando considera probada una conducta ilegítima pero sin reunirse los requisitos prescritos para la aplicación de la pena hadd, sanción que, en todo caso, deberá ser inferior a esta pena.

De este modo, el delito de fornicación ilícita quedará configurado en el Derecho islámico clásico en torno a dos ejes fundamentales que lo caracterizarán. El primero es el de su condición de delito hadd, prescrito en el propio Corán, lo que hacía que sus disposiciones fueran, al menos en teoría, aplicadas, de un modo más o menos uniforme, en todo tiempo y lugar, en Dār al-Islām. El segundo es el del equilibrio establecido entre la severidad de sus penas y las dificultades prácticas para poder ser probado. Se trata de una cuestión fundamental que ha hecho posible que este sistema haya mantenido su vigencia a lo largo de siglos en las diferentes sociedades islámicas.

\section{EL DELITO DE FORNICACIÓN ILÍCITA EN EL DERECHO CONTEMPORÁNEO DE LOS PAÍSES ÁRABES. POSTURAS}

Sin embargo, la transición hacia el periodo contemporáneo ha producido numerosos cambios en la configuración jurídica de los Estados árabes contemporáneos. Así, la legislación penal contemporánea de los países árabes en materia de relaciones sexuales ilícitas nos muestra de un modo claro como su formación ha oscilado entre dos fuentes jurídicas bien identificables. Por una parte se aprecia una clara influencia del Derecho penal de los países europeos que colonizaron estos países a partir del siglo XIX, con una especial mención para el Derecho francés napoleónico. Por otra parte, es posible reconocer una influencia creciente del Derecho Penal de la $\breve{S} a r{ }^{`} a$ e en los términos anteriormente descritos. De hecho, y como se verá más adelante, en ciertos países, está actuando como un modelo de reacción ante la influencia jurídica de los países occidentales en el mundo árabe ejercida durante y tras el periodo colonial.

Realmente, en lo que se refiere al tratamiento penal del delito de fornicación ilícita ambas tradiciones jurídicas muestran una cierta convergencia de criterios,

\footnotetext{
${ }^{6}$ Aunque la Escuela malikí también admite como prueba circunstancial del delito el embarazo de la mujer soltera. Cfr. MĀLIK b. ANĀS, Muwatță' 42, 8, Beirut, Mu'asasa al-ma'āruf, 2004, p. 429.

${ }^{7}$ Corán, 4, 15: "Llamad a cuatro testigos de vosotros contra aquéllas de vuestras mujeres que cometan deshonestidad. Si atestiguan, recluidlas en casa hasta que mueran o hasta que Alá les procure una salida”. CORTÉS, Julio, 2005, Op. Cit., p. 124.

${ }^{8}$ SIDIAHMED, Abdel Salam, Op. Cit., p. 192.
} 
pero también un importante grado de incompatibilidad que, en buena medida, resulta representativo de la tensión dialéctica que ha acompañado la propia evolución de la legislación penal en los países árabes.

Siguiendo el criterio de la fuente jurídica en la que se inspira la legislación sobre el delito de fornicación ilícita podemos establecer una clasificación de los países árabes en tres grupos principales. El primero de ellos incluye a aquellos países que han regulado esta cuestión siguiendo los patrones del Derecho Penal de los países europeos, especialmente de Francia. Un segundo grupo lo componen aquellos países que han optado por un sistema mixto en el que incluyen algunos elementos propios de la $\breve{S}_{a r \bar{T}} a$ dentro de un marco general inspirado por el Derecho penal de los países europeos. Finalmente un tercer grupo lo formaría aquellos países que regulan esta cuestión siguiendo, de modo preferente o integral, las disposiciones de la $\breve{S} a r{ }^{\top} a$ a, estableciéndose en este grupo una subdivisión entre los países que han aplicado este derecho de modo interrumpido desde su independencia y los que, en un momento determinado de su historia, optaron por sustituir una legislación de inspiración occidental por otra, basada en las prescripciones del Derecho Islámico.

\section{ASIMILACIÓN DEL DELITO DE FORNICACIÓN ILÍCITA (ZINĀ) A LAS CATEGORÍAS JURÍDICO-PENALES DE TRADICIÓN EUROPEA}

Partiendo de la base de las diferencias lógicas entre los procesos de implantación del derecho penal occidental en los distintos países árabes, existe un grupo de países formado por Argelia, Túnez, Egipto, Líbano, Siria, Jordania, Irak, Bahrein y Kuwait en el que se presenta una clara similitud en aspectos sustanciales y procesales en sus disposiciones penales sobre el delito de fornicación ilícita.

Se trata, de un grupo de países heterogéneo cuya semejanza en el tratamiento jurídico de la materia que nos ocupa no responde a una proximidad geográfica ni temporal, ya que adoptaron progresivamente su legislación sobre esta cuestión, a lo largo de más de noventa años. Sin embargo, la adopción de la legislación penal en estos países va a situarse en un contexto semejante; el de la descolonización de las potencias occidentales y la formación de nuevos ordenamientos jurídicos de tipo territorial, y destinados a sustituir el pluralismo jurídico propio del periodo colonial. Esta es una circunstancia fundamental a la hora de comprender los paralelismos existentes en la legislación sobre relaciones sexuales ilícitas entre estos países, que pasamos a analizar de un modo más detallado.

\subsection{CONTEXTO HISTÓRICO}

A pesar de tratarse todos ellos de países árabes que, durante una buena parte de su historia reciente, estuvieron sujetos al dominio colonial por parte de potencias extranjeras, los contextos histórico-jurídicos en los que adoptaron sus legislaciones sobre la materia que nos ocupa son tan variados como su distribución geográfica en distintas regiones del planeta. Esta adopción varía considerablemente entre aquellos países que establecieron sus Códigos Penales durante la época colonial, como es el 
caso de Egipto (1883), Túnez (1913) e Irak (1917), y que posteriormente los adaptaron tras obtener su independencia y el de aquellos países que aprobaron por primera vez su propia legislación penal tras obtener la independencia, a partir de la década de los años 40.

Sin embargo, a pesar de la distancia temporal, la legislación penal de estos países se ha ido nutriendo de una serie de fuentes comunes que se han ido transmitiendo sucesivamente hasta desembocar en los Códigos Penales actualmente vigentes. La principal de estas fuentes es el Derecho Penal francés, adoptado sucesivamente por estos países, bien de modo un directo, o bien a través de otros Códigos Penales inspirados por aquel, como el Código Penal otomano de 1858.

Una constante que se verificará en la codificación penal de los países árabes será la de la influencia que ejercerán unos Códigos sobre otros a medida que las nuevas naciones árabes alcanzan su independencia y crean su propio ordenamiento jurídico-penal.

En este sentido, la experiencia vivida en Egipto en 1883 con la primera codificación penal del mundo árabe, basada en el Código Napoleónico de 1810, marcaría el inicio de un proceso histórico en el que, a lo largo del siglo XX, un número importante de países árabes desarrollarán su Derecho Penal a partir de fuentes similares y con resultados igualmente similares.

De hecho, el resultado de la experiencia codificadora egipcia serviría como una referencia clara por parte de las autoridades coloniales británicas para la introducción de una nueva legislación penal que sustituyera a la vigente en los territorios que a partir de la Primera Guerra Mundial fueron ganados al Imperio otomano.

El primero de estos territorios al que sería exportada la experiencia codificadora egipcia sería Irak. Tras la conquista británica de la Wilāya de Basora, en 1917, y de la de Bagdad, en 1918, las nuevas autoridades aprobarían el llamado Código de Bagdad, un nuevo texto penal que respondía a los principios fundamentales de la legislación otomana y del Código penal egipcio de 1905. Este texto, tras ser modificado en diversas ocasiones, sería el fundamento del actual Código penal de $1966^{9}$.

Sin embargo, la adopción de la legislación penal de tipo europeo en estos países no se debió exclusivamente a una opción de las potencias colonizadoras. De hecho, tras el proceso de independencias desarrollado a partir de la Segunda Guerra Mundial, los nuevos Estados árabes optarán por dotarse de una serie de Códigos Penales basados en el Derecho de los países europeos, y principalmente de Francia. El primero de estos países fue Líbano, que en 1943 aprobaría un Código Penal que, en su momento fue considerada la más importante codificación penal de Oriente Medio por su calidad técnica y su espíritu modernizador ${ }^{10}$. Por ello, este texto trasplantado de modo casi literal en Siria, en el Código de 1949, e igualmente, actuaría como fuente principal del Código Penal de Jordania de 1951.

El caso de Argelia, por su parte, responde a un contexto jurídico específico, como es el de la continuidad jurídica del Derecho Penal tras el periodo colonial. De

\footnotetext{
${ }^{9}$ Irak. Qānūn al-`uqūbāt raqm 111 li sana 1966.

${ }^{10}$ HOSNI, Naguib: "La législation pénale dans le monde arabe", Revue de Science Criminelle et de Droit Pénal Comparé, 1, (1967), p. 799.
} 
hecho, tras obtener su independencia, en 1962, el nuevo Estado argelino continuará aplicando en su territorio la legislación penal francesa hasta 1966, año en el que sería aprobado un nuevo Código Penal ${ }^{11}$, que, con diversas enmiendas, es el que se mantiene vigente hoy día. Por lo tanto su principal fuente de inspiración será el Derecho Penal francés vigente en los años 60.

Finalmente, una excepción a este predominio de las fuentes francesas en la legislación penal de estos países esta constituida por Bahrein y por Kuwait. En el caso de Bahrein, en cuanto parte integrante del Imperio británico, recibiría en 1956 el Código penal Anglo-indio de 1860. Este texto sería la fuente principal del primer Código que este país promulgaría en 1976, tras su independencia, así como del Código Penal de Kuwait de 1960.

\subsection{EL ÁMBITO MATERIAL DEL DELITO: DE LA FORNICACIÓN ILÍCITA AL ADULTERIO}

El principal efecto de la asimilación de los modelos jurídicos europeos en la regulación del delito de zināen este grupo de países se refiere al ámbito material del delito. Siguiendo la raíz común, constituida por la regulación del Código Penal napoleónico de $1810^{12}$, asimilada de modo directo o bien a través del Código otomano de 1858 o de las codificaciones penales árabes, como la egipcia o la libanesa, el Derecho Penal de este grupo de países coincidirá en un aspecto fundamental como es el de asimilar, a efectos penales, la categoría jurídica de la zinā, dentro del tipo jurídico del adulterio ${ }^{13}$.

La principal consecuencia de esta medida es la de que su campo de aplicación subjetiva queda notablemente restringido al limitarse a las personas casadas, sustituyendo al ámbito, de la "relación sexual ilegítima" que desarrollaron las Escuelas Jurídicas clásicas islámicas, y que abarcaba el contacto sexual entre personas que no estuvieran vinculadas entre sí por un matrimonio.

En este sentido, mientras que en el derecho islámico clásico el hecho de que las personas que cometieran este delito fueran casadas no constituía más que una circunstancia agravante de la pena, tal y como pudimos apreciar anteriormente, en el Derecho penal de estos países pasará a constituir el único aspecto penalmente relevante de las relaciones sexuales ilícitas, y que aparece referido, en sus versiones originales en lengua árabe, bajo el término zinā.

Asimismo, los Códigos Penales de estos países coinciden en aplicar la misma sanción penal al coautor del delito, (̌̌arīk) en la relación sexual con una persona casada. Sin embargo, y dado que los Códigos Penales de estos países no sancionan la fornicación entre personas solteras, parece ser necesario el concurso de un

${ }^{11}$ Argelia: Code pénal. Ordonnance $\mathrm{n}^{\mathrm{o}}$ 66-156 du 18 șafar correspondant au 8 Juin 1966 portant Code pénal. Journal Officiel de la République Algérienne, n 49, 11 juin 1966, p. 529.

${ }^{12}$ Francia: Códe pénal de 1810: « Section IV. - attentats aux mœurs. Arts. 336-340.

${ }^{13}$ Esta conducta penal aparece tipificada en los Códigos penales de los siguientes países: Egipto, Arts. $^{\circ} 274$ (adulterio por parte de la esposa) y 277 (adulterio por parte del esposo), Túnez, Art. ${ }^{\circ}$ 236, Argelia, Art. ${ }^{\circ} 339$, Líbano, 478 (adulterio de la esposa) y 488 (adulterio del esposo), Siria, Art. ${ }^{\circ} 473.1$ (adulterio de la esposa) y 473.2 (adulterio del esposo), Jordania, Art. ${ }^{\circ} 282$ (adulterio de la esposa) y 283 (adulterio del esposo), Irak, Art. ${ }^{\circ} 377$, Kuwait, Art. $^{\circ} 195$ y Bahrein, Art. 316. 
elemento volitivo en el cómplice del adulterio, como es el de tener conocimiento de que la persona con la que se está consumando una relación sexual está casada. La apreciación de esta circunstancia determinante quedaba, por tanto, en manos del juez a la hora de sancionar este delito ${ }^{14}$.

Por ello, en las codificaciones más recientes, como la argelina de 1966, o la iraquí de 1969, se especifica que la responsabilidad penal del cómplice de un adulterio sólo se aplica cuando éste sepa que la mujer con la que consuma una relación sexual está casada ${ }^{15}$, lo cual no deja de establecer una clara discriminación penal por causa de género, ya que la mujer cómplice de adulterio queda sujeta en todos los casos a la misma pena que el adúltero, independientemente de que conociera o no la condición de casado de éste último.

\subsection{LA DIFERENCIACIÓN DEL TIPO Y DE LA PENA POR CAUSA DE GÉNERO}

De hecho, un rasgo característico de la regulación del delito de zinā en este grupo de países ha sido el de la diferenciación de la conducta delictiva por razón de género. Esta circunstancia encuentra su origen en las principales fuentes en la que se inspiró el Derecho penal de estos países, esto es, el Código napoleónico de 1810 y el otomano de 1858, que establecían una clara distinción de género en el tipo delictivo de las relaciones sexuales extramaritales.

Realmente, tal y como se puede apreciar en estos textos, el legislador estableció dos tipos penales diferentes, con una sanción diferente para las relaciones sexuales extramaritales cometidas por la mujer y por el varón. Así se puede apreciar como apenas en el caso de la mujer, la relación sexual extramarital era calificada como adulterio y era sancionada, en cualquier circunstancia, con pena de cárcel, mientras que, en caso del varón, desaparece la calificación de adulterio para sus relaciones sexuales extramaritales, que apenas resultaban punibles cuando se mantuvieran con una concubina y dentro del domicilio conyugal, siendo la pena limitada a una sanción pecuniaria. ${ }^{16}$

Este esquema diferenciado por razón de género será utilizado primeramente como base para la regulación de este delito en el Código Penal egipcio de 1883, y, posteriormente en los textos penales del resto de países que conforman este grupo.

En este sentido, estos textos coinciden en que la pena establecida para la mujer adúltera es superior a la del varón y se aplica en todos los casos, mientras que la del adúltero sólo se aplica si el hecho delictivo se hubiera desarrollado en el domicilio conyugal. Por lo tanto, existe una importante diferencia en la naturaleza jurídico-

${ }^{14}$ Cfr. GRANDMOULIN, Jacques: Le Droit Pénal Égyptién Indigène, Imprimerie Nationale, El Cairo, 1908. p. 342.

${ }^{15}$ Argelia: Qānūn al- 'uqūbāt m. 339. Irak: Qānūn al- 'uqūbātm. 377.

${ }^{16}$ Código Penal francés de 1810, Art. 339: «Le mari qui aura entretenu une concubine dans la maison conjugale, et qui aura été convaincu sur la plainte de la femme, sera puni d'une amende de cent francs à deux mille francs. »

Código Penal otomano de 1858, Art. 201: "Le mari qui entretiendra un commerce adultérin dans la maison conjugale et qui aura et convaincu sur la plainte de sa femme sera puni d'une amende de cinq a cent medides d'or". 
penal de la conducta de ambos cónyuges, ya que la relación sexual extramarital de la esposa es un delito instantáneo e independiente del lugar de su consumación mientras que la del varón ha de revestir un elemento de continuidad, es decir una habitualidad que concurra con un elemento cualificador, este es el de "mancillar" el domicilio conyugal ${ }^{17}$

Sin embargo, se puede apreciar, ya desde la recepción que se producirá en Egipto del Derecho napoleónico, como se producirán algunas diferencias que muestran algún intento por parte del legislador árabe, de conciliar la legislación napoleónica con la tradición jurídica islámica precedente.

Así, por una parte, a diferencia del Derecho napoleónico, el derecho penal de estos países recuperará la misma terminología penal utilizada en la šarī’a, o sea, $z i n \bar{a}$, para calificar tanto las relaciones sexuales extramaritales cometidas por el esposo (al-zānî̀) como las de la esposa (al-zānia) que pasan, por tanto, a ser agentes de un mismo delito.

Por otra parte, los Códigos Penales de estos países reducirán, en cierta medida, la desproporción de la pena entre ambos cónyuges existente en el Código napoleónico, sustituyendo la mera sanción pecuniaria del esposo adúltero, allí prevista, por la condena a prisión, aunque por un periodo muy inferior al de la esposa.

Finalmente, el hecho de aplicarse la misma sanción penal al cómplice del adulterio de la mujer, a pesar de que el cómplice sea casado y autor, al mismo tiempo de otro delito de adulterio provoca que la sanción penal para ambos sea equiparada, siempre y cuando, la denuncia provenga del marido de la mujer adúltera.

Este esquema diferenciado de la pena y del tipo penal entre el marido y la esposa, propia de una legislación de raíz decimonónica, alcanza su mayor proporción en los Código penales más antiguos como el egipcio de $1937^{18}$, o el libanés de $1943^{19}$. Sin embargo se puede apreciar como esta desproporción se reduce en otros Códigos más modernos, como el argelino de $1966^{20}$, para pasar a ser progresivamente eliminada durante las últimas décadas y a través de diferentes enmiendas, en los Códigos Penales de Túnez, Argelia, Kuwait, y Bahrein.

En el caso de Túnez, esta opción del legislador se encuadraría dentro de la política en favor de los derechos de la mujer, promovida por Habīib Būrqība ${ }^{21}$, acabaría por tener su reflejo en la legislación penal y, más concretamente en la regulación del delito de adulterio. Así, a través de una Ley de $1968^{22}$, se establecería el mismo tipo y la misma sanción penal para el adulterio del marido y de la mujer,

\footnotetext{
${ }^{17}$ GRANDMOULIN, Jacques., 1908, Op. Cit., p. 299.

${ }^{18}$ Pena de prisión por un periodo de hasta 2 años para la mujer y hasta 6 meses para el marido.

${ }^{19}$ Pena de prisión por un periodo entre tres meses y 2 años para la mujer y entre 1 mes y 1 año para el marido.

${ }^{20}$ Pena de prisión por un periodo entre 1 y 2 años para la mujer y entre seis meses y 1 año para el marido.

${ }^{21}$ Sobre esta cuestión Vid. MURPHY, Emma. "Women in Tunisie: Between State Feminism and Economic Reform", en DOUMATO, Elleanor. y POSUSNEY, Marsha, (Eds.), Women and Globalization in the Arab Middle East: Gender, Economy and Society. Lynner Rienner Publishing, Boulder, 2003 p. 169-192.

${ }^{22}$ Túnez, Qānūn `adad 1 li-sana 1968 al-mu'raj 8 mārs 1968.
} 
así como para sus cómplices, sustituyendo la anterior legislación basada en el modelo egipcio. Se trató de un importante cambio en la configuración de este delito en un país árabe, ya que se establece una severa sanción de 5 años de prisión y una multa, pero que puede quedar automáticamente reducida al pago de la multa si no concurre ninguna circunstancia agravante como es la comisión del delito dentro del domicilio conyugal.

Un camino semejante sería seguido por Argelia en 1982 cuando a través de una Ley ${ }^{23}$ que enmendó su Código Penal se estableció que la pena prevista para el adulterio cometido por el esposo sería elevada hasta situarse al mismo nivel que el de la esposa, es decir, una condena a prisión por un periodo de entre 1 y dos años.

Finalmente, en el caso de Kuwait y de Bahrein nunca se llegó a verificar esta discriminación penal por razón de género. Esto se debió a diversos motivos, entre los que cabe destacar dos factores como son la fecha de promulgación de sus Códigos, así como las fuentes en las que se inspiran. Por una parte, hay que tener en cuenta que los Códigos de estos países, de 1960, en el caso de Kuwait, y en 1976 en el de Bahrein, se encuentran muy alejados de las primeras codificaciones penales árabes, y se enmarcan en un momento en el que tanto el Derecho Penal como el Internacional comienzan a incidir de un modo particular en la igualdad de género en la legislación positiva. Igualmente, cabe referir la fuente de la que se inspiraron estos países para la regulación del delito de adulterio, que fue el Código Penal anglo-indio de 1860, de raíz anglosajona y en el que, a diferencia de la legislación francesa, acabaría por establecer una misma sanción penal para el adulterio del marido y de la esposa.

De hecho, a diferencia del Código francés, el Código Penal Anglo-indio de 1860 apenas penaba al hombre que, independientemente de su Estado Civil, mantuviera relaciones sexuales con una mujer casada sin consentimiento de su marido. Sin embargo, el legislador británico consideró que esta legislación, por sí sola, no respondía fielmente a las condiciones sociales presentes en los países árabes. Por ello, cuando en 1899 fue aplicado en Sudán, por las autoridades británicas, un Código Penal basado en la legislación anglo-india de 1860, la regulación del adulterio sería completada con un nuevo artículo en el que la mujer adúltera también era sancionada con la misma pena de prisión que el hombre ${ }^{24}$, estableciendo un antecedente para la legislación de otros territorios árabes sometidos a la Corona británica, como era el caso de Bahrein y de Kuwait.

En consecuencia, los Códigos Penales de estos dos países establecerían la misma pena de prisión para el adulterio del marido y el de la mujer, que quedan subsumidos dentro de la categoría general de "persona casada" (šajș mutazawwaŷ) en Kuwait, y de "cónyuge" (zawy) en Bahrein, y quedan sometidos a una condena que podrá alcanzar en Kuwait hasta un máximo de 5 años de prisión mientras que, en el caso de Bahrein, esta sanción se reducirá a 2 años de prisión, tras la aprobación del nuevo Código de 1976.

\footnotetext{
${ }^{23}$ Argelia, Qānūn 'adad 4 li-sana 1982 al-mu'raj 13 fabrāīr 1982.

${ }^{24}$ Sudán: The Sudan Penal Code. 1899. (art. 406).
} 


\subsection{LA LEGITIMIDAD PROCESAL Y LOS MEDIOS DE PRUEBA}

La importación en estos países de la legislación penal occidental conllevará igualmente, importantes cambio de tipo procesal en el tratamiento del delito de zinā. Uno de estos cambios afecta a la legitimación procesal para iniciar un proceso penal por este delito. De este modo, en estos países, siguiendo el precedente del Código egipcio, el procesamiento del adúltero o adúltera solamente se puede llevar a cabo mediante denuncia del cónyuge, quien, en la mayoría de los casos, tiene capacidad para detener el proceso en cualquier fase anterior a la sentencia penal. ${ }^{25}$ Esto, sitúa el delito de zinā fuera de la lógica del delito contra las disposiciones divinas que podía ser denunciado por cualquier testigo del acto y que no podía ser perdonado, según establece la Šarī́a y lo sitúa en el contexto de un crimen privado contra el honor del cónyuge ofendido y que, por tanto, no afecta a los intereses del Estado.

En lo que se refiere a los medios de prueba del delito, la legislación penal de estos países adoptará, igualmente, los medios establecidos en el Derecho Penal francés para este tipo de delito, o sea, el flagrante delito atestiguado por un Agente Judicial, la confesión judicial o el reconocimiento a través de cartas u otros documentos.

\section{LOS SISTEMAS MIXTOS: ASIMILACIÓN PARCIAL DEL DERECHO ISLÁMICO TRADICIONAL}

En segundo lugar, podemos identificar un grupo de Estados, formado por Marruecos, y Omán, que ha optado, por diferentes razones, por introducir una serie de elementos propios del Derecho Islámico tradicional en su legislación penal sobre las relaciones sexuales ilícitas. Estos elementos afectarán básicamente a cuestiones sustantivas, como es el ámbito material del delito, aspecto en el que adoptarán una orientación que se apartaba de la tendencia restrictiva seguida por la mayoría de países árabes que, hasta aquel momento, habían adoptado los modelos penales de tipo occidental. Sin embargo, esta extensión del ámbito material del delito aparecerá combinada con una estructura jurídica, en lo referido al procedimiento y al sistema de penas que responde plenamente a dicha tradición jurídica del Derecho Penal occidental, por lo que se crea una nueva vía que podemos calificar como un "sistema mixto".

En el caso de Marruecos, su legislación penal sobre esta cuestión muestra un conjunto de particularidades que la diferencian del resto de países del Norte de África y que, en gran medida, encuentran su origen en el contexto histórico en el que se produjo la codificación de su Derecho Penal. El proceso de colonización que vivió Marruecos a lo largo de la primera mitad del siglo XX, con la instauración de dos Protectorados, francés y español, y con el Estatuto de la zona internacional de Tánger llevaría a la implantación progresiva de un pluralismo jurídico en el que hasta cuatro legislaciones penales diferentes serían aplicadas simultáneamente en

\footnotetext{
${ }^{25}$ Aunque en algunos casos, como el de Bahrein, junto con el cónyuge ofendido, tanto el Ministerio Público como los agentes de la autoridad también tienen capacidad para iniciar este proceso.
} 
función del territorio y de la personalidad de los encausados ${ }^{26}$. Así, en la parte sur sería aplicado el Código Penal francés, promulgado en Marruecos en 1913, mientras que la parte norte, por una parte, sería aplicado el Código Penal español, promulgado en 1914, y por otra, la Zona Internacional de Tánger tendría su propia legislación penal derivada de su Estatuto. Estas legislaciones serían aplicadas con un carácter personal, es decir, siempre que en un conflicto jurídico, al menos una de las partes fuera un extranjero. Por ello, habrían de coexistir con una cuarta jurisdicción dirigida a la población indígena y que era ejercida por las autoridades locales basándose en el Derecho Consuetudinario local.

Por ello la unificación del Derecho penal se convertiría en una necesidad para el futuro Estado independiente marroquí. Así, y en virtud del compromiso estipulado en el Tratado del Protectorado, Francia se comprometió a "reformar la justicia indígena", iniciando una serie de reformas que conducirían a la aprobación del Código Penal de 1953, redactado por una Comisión mixta franco-marroquí, con el que se pretendía unificar la jurisdicción penal en la parte del Protectorado francés. Este texto, que trataba de introducir un derecho penal moderno de aplicación territorial, estaba basado fielmente en la legislación francesa; sin embargo, dada su vocación unificadora, habría de adaptarse a las particularidades políticas y sociales de Marruecos, así como a los principios de la moral y de las tradiciones del país. Tal y como confirmaría posteriormente el Presidente de aquella Comisión: "Il avait été demandé à la comisión d'elaborer un texte qui ne fût pas la reproduction intégrale du Code pénal français et qui restât, tout en étant moderne, spécifiquement marocain». Según sus palabras, aquella comisión codificadora "procédé d'une pensée française nourrie d'expériences marocaines et d'une science musulmane astreinte à la logique française ${ }^{27}$

El Código del Protectorado francés serviría como base fundamental para el primer Código Penal del Marruecos independiente, promulgado en $1963^{28}$. Este texto responderá a una estructura y a un contenido sustantivo claramente inspirados en el Derecho Penal francés pero, al mismo tiempo, se separará de aquella fuente en aspectos relevantes relacionados con la moral y las costumbres sociales, lo que afectará de un modo claro a la regulación del delito de fornicación ilícita.

Esta circunstancia se aprecia claramente en lo relativo al ámbito material del delito. Así, a diferencia de la tendencia restrictiva seguida, en este aspecto, por el resto de los Códigos penales árabes promulgados en aquella época, el Código marroquí de 1963 introduce un criterio material extensivo a la hora de definir los contornos de este delito.

En este sentido, se establece en dicho texto un tipo penal, que recupera la esencia de la definición del delito de fornicación ilícita del derecho islámico clásico,

${ }^{26}$ Cfr. FASSI-FIHRI, Mohamed: "La législation pénale du Maroc", Revue de Science Criminelle et de Droit Pénal Comparé, (1968), p. 13-14.

${ }^{27}$ Cfr. AMZAZI, Mohieddine: "Islam et Droit Pénal au Maroc", Archives de Politique Criminelle, 9, 1987, p. 252-253.

${ }^{28}$ Marruecos: Zahīr Šarīf raqm 1.59.413 bi-l-musadaqa 'alà maŷmū'a al-qānūn al-ŷanā'ī. 
y según el cual son penalizadas las relaciones sexuales consumadas entre las personas de distinto sexo que no estén unidas entre sí por un vínculo matrimonial ${ }^{29}$.

Seguidamente, el legislador marroquí establece un tipo penal para los casos en los que el participante en una relación sexual está casado, y que, por esta razón, está incurriendo en una práctica de adulterio. Realmente, esta regulación del delito de adulterio se aleja de la legislación de inspiración francesa y queda configurada como una circunstancia agravante de la pena prevista para el delito de relación sexual ilícita establecida en el artículo anterior, lo que justifica que no se establezca distinción entre el adulterio cometido por el esposo y el de la esposa a la hora de determinar la pena, a pesar de tratarse de una legislación anterior a las reformas igualitarias que serían promovidas más adelante en otros países árabes.

Sin embargo, en los aspectos procesales, tanto el delito de relaciones sexuales extramaritales como el adulterio van a responder a criterios propios del Derecho Penal francés, lo que se refleja tanto en la legitimación activa en el caso del adulterio, reservada al cónyuge ofendido, como en la capacidad de este cónyuge denunciante de detener, a través del perdón, tanto el proceso judicial como la condena de prisión ${ }^{30}$.

Esta influencia también se refleja, tanto en la punición, restringida a la pena de prisión $^{31}$, como en los medios de prueba admitidos para demostrar la existencia del delito. Lejos de los medios probatorios testimoniales establecidos por el fiqh malikí, el Código marroquí reproducirá los medios probatorios establecidos en el Derecho Penal francés para el delito de adulterio, o sea, el flagrante delito atestiguado por un Agente Judicial, la confesión judicial o el reconocimiento a través de cartas u otros documentos ${ }^{32}$.

Otro país que responde a este sistema es Omán, cuya legislación penal surgirá en un contexto general que presenta un cierto paralelismo con el caso de Marruecos desde el punto de vista del desarrollo de una política legislativa dirigida a la instauración de un Derecho Penal territorial sobre todo el país. Omán, a pesar de no haber sido formalmente objeto de un Protectorado o de una colonización efectiva durante el siglo XX, por su posición geográfica estratégica para la navegación internacional ha sido históricamente un área de influencia disputada por Francia y por Gran Bretaña ${ }^{33}$. En consecuencia, y tras firmar una serie de Acuerdos comerciales con este último país, se estableció, a partir de 1951, la aplicación de la jurisdicción británica en las causas civiles y penales iniciadas contra los ciudadanos británicos o contra nacionales de países de la Commonwealth que no fueran musulmanes, formalizándose una situación de pluralismo jurídico en el que la

${ }^{29}$ Id. Art. 490.

${ }^{30}$ Id. Art. 492. Sin embargo, el Código marroquí establece una excepción por la que se otorga legitimidad activa al Ministerio Fiscal cuando el adulterio de práctica con "pública notoriedad" y el otro cónyuge se encuentra fuera del territorio nacional.

${ }^{31}$ Pena de prisión entre un mes y un año para las relaciones sexuales extramaritales y pena de de prisión entre un año y dos por adulterio. Arts. 490 y 491.

${ }^{32}$ Id. Art. 493.

${ }^{33}$ BAHARNA, Husain M. Al-: The legal Status of the Arabian Gulf States. Rückent, 1968, p. 47. 
legislación británica coexistiría con el Derecho Islámico tradicional, aplicado para el resto de la población por los tribunales locales.

A este factor se unirá el drástico cambio político producido en el país tras el triunfo en 1970 de un Golpe de Estado promovido por Qābūs bin Sa ēîd, contra su padre, el Sultán Sa īd bin Taymūr. Este Golpe, apoyado por Gran Bretaña, marcaría el inicio de un proceso de modernización del Estado y del ordenamiento jurídico, con la creación de un Ministerio de Justicia, el desarrollo de una Jurisdicción territorial y la promulgación de un Código Penal, en el año 1974 ${ }^{34}$. Este texto, redactado bajo el asesoramiento de juristas sirios y británicos, y basado, en gran medida, en los Códigos Penales de Bahrein y de Kuwait, debía de responder al desafío de sustituir en los tribunales a la legislación islámica tradicional ${ }^{35}$.

Estos factores pesaron definitivamente para que la regulación penal sobre las relaciones sexuales ilícitas no asimilara en su totalidad los modelos legislativos occidentales, tal y como venía sucediendo en la mayoría de los países árabes hasta aquel momento.

En su lugar, el legislador omaní optará por realizar un cambio normativo menos drástico, estableciendo un sistema mixto semejante al que había sido promulgado una década antes en Marruecos. En este sentido, el delito de zinā es definido como una cópula ( $f i^{\top} \%$ al-ŷimā $)$ entre un hombre y una mujer que no estén unidos por un contrato matrimonial válido legalmente ${ }^{36}$. Esto supone, por tanto, la aplicación de un criterio extensivo del concepto de relación sexual ilícita, que sobrepasa el ámbito del adulterio y que se extiende a toda relación sexual extramarital, conforme al criterio de la Sar'̄'a. Seguidamente, al igual que se establece en el Derecho marroquí, el Código Penal de Omán incluye un artículo en el que se configura el delito de adulterio como un elemento agravante de la pena del delito de zinā, y no como un delito independiente. Esto supone un cambio en la lógica procesal de este delito que ya no responde a los presupuestos del Derecho francés, lo que se muestra en la ausencia de cualquier discriminación por razón de género en la configuración del delito y en el establecimiento de la pena.

Sin embargo, y al igual que sucede en el Código marroquí, este esquema sustantivo aparecerá encuadrado dentro de unas condiciones procesales propias de los sistemas jurídicos de raíz occidental, que se encontraban establecidos en la mayoría de los países árabes hasta aquel momento. En este sentido cabe interpretar que el sistema punitivo previsto se limite a las penas de prisión ${ }^{37}$, en lugar de los castigos físicos, o bien en el hecho de que, en el caso de adulterio, la legitimación activa para iniciar el proceso penal corresponda apenas al cónyuge ofendido o a su tutor legal, los cuales, en todo momento pueden detenerlo, así como la ejecución de la condena, a través del perdón. Asimismo, tal y como sucedía en el código

\footnotetext{
${ }^{34}$ Omán: Qānūn al- uqūbāt bi-marsūm sultāîî raqm 7 li-'ām 1974.

${ }^{35}$ Sobre el proceso de redacción de este texto Vid. ALLEN, Calvin y LYNN, W. Oman under Qaboos: From Coup to Constitution, 1970-1996, Marshall University, 2000, p. 59.

${ }^{36}$ Omán:, Qānūn al- 'uqūbāt, m. 225.

${ }^{37}$ Pena de prisión entre tres meses y un año para las relaciones sexuales extramaritales y pena de prisión entre un año y tres, por adulterio. Arts. 225 y 226.
} 
marroquí, el legislador omaní estableció una excepción aquella exclusividad de legitimación activa, según la cual en el caso de ausencia del territorio nacional de uno del otro cónyuge o del tutor legal, se permite al Ministerio Fiscal iniciar el procedimiento de oficio; eso sí, tras haber conminado al adúltero a abandonar su actitud y no haber sido seguida esta advertencia, lo que no deja de ser una importante desviación con respecto al criterio de la imposibilidad de perdón ante un delito hadd, seguido por la Jurisprudencia clásica ${ }^{38}$.

\section{LEGISLACIÓN BASADA EN LA ŠARI'A: VÍAS DE ADOPCIÓN}

El tercer grupo, que completa esta clasificación, está formado por aquellos países cuya legislación penal sobre el delito de fornicación ilícita (zina) , responde de un modo completo o casi completo, a las disposiciones de la Šar $\bar{r}^{\prime}$, tal y como fue interpretada por la Escuelas Jurídicas clásicas.

Este grupo lo forman aquellos países que a lo largo de su historia como Estados independientes siempre aplicaron de modo integral la $\breve{S} a r \bar{r}^{\prime} a$ ante este tipo de delitos, como es el caso de Arabia Saudí, Emiratos Árabes, Yemen o de Qatar, así como aquellos países que, habiendo adoptado inicialmente una legislación penal de tipo europeo, en un momento determinado optaron por reimplantar las disposiciones del Derecho Islámico ante este tipo de delitos, tal y como sucedió en Libia, en 1973, y en Mauritania y Sudán, una década después.

\subsection{LA REINSTAURACIÓN DEL DERECHO ISLÁMICO CLÁSICO}

\subsubsection{Contexto histórico}

En 1972, tres años después del Golpe de Estado que le llevaría al poder en Libia, el Coronel Qadd̦āfì sorprendía al mundo al anunciar la instauración de la pena de amputación ante los delitos de robo y de bandidaje, con base a las disposiciones de la Šarīa. Esta iniciativa surgía en un momento en el que el Derecho Penal islámico parecía en la mayoría de los países árabes ser una mera reminiscencia históricojurídica. Este primer paso sería seguido por nuevas normas a través de las cuales el legislador libio se proponía moralizar la vida pública a partir de la reinstauración en el ordenamiento penal de las sanciones establecidas por la Šarī'a ante ciertos delitos ḥudūd como la fornicación ilícita (zina) y la falsa acusación de este delito (qadff).

De este modo, se iniciaba un nuevo movimiento de islamización del Derecho Penal que posteriormente se extenderá a Mauritania y a Sudán y a otros países islámicos, como Irán y Pakistán o Nigeria. En el caso de los países árabes, salvando las lógicas diferencias contextuales en las que estos procesos se desarrollan, existen una serie de elementos que los aproximan.

\footnotetext{
${ }^{38}$ Omán: Qānūn al- 'uqūbāt, m. 227.
} 
Por una parte, este movimiento contará con una corriente social de apoyo, presente en amplios sectores del mundo árabe, que se remonta a los primeros años que siguieron a la importación de las normas penales de tradición occidental en los Códigos Penales de los nuevos países árabes independientes. Este brusco cambio en la evolución jurídica de estos países, unido a las propias carencias de los nuevos Estados independientes provocará una respuesta en amplios sectores de las sociedades de estos países. Estos sectores, agrupados en una serie de movimientos, denominados posteriormente "islamistas", abogarán por una vuelta a unas costumbres islámicas tradicionales, a su juicio, corrompidas durante la colonización extrajera, a través de la restauración de la Šarīa como medio de moralizar la vida pública y la acción del Estado.

Por otra parte, el contexto político en el que surgirá esta islamización del Derecho Penal no responderá a una situación de continuidad o de "desarrollo natural" de los ordenamientos jurídicos de estos países, sino que se encuadran en una lógica revolucionaria de su política legislativa en momentos particularmente convulsos de su historia.

En el caso de Libia, como hemos dicho anteriormente, este proceso nace tras un Golpe de Estado ejecutado en 1969 por un grupo de oficiales, fuertemente influidos por la ideología pan-arabista naserista que acabaría con la monarquía del Rey Idrīs I, acusado de haber dirigido la nación conforme a los intereses de los países occidentales y de haber corrompido la moral pública a través de la adopción de legislación extranjera y ajena a las tradiciones del país. En coherencia con este discurso político, una de las primeras medidas del nuevo gobierno sería la instauración de un comité encargado de presentar propuestas para la introducción de la $\breve{S} a r \bar{t}^{\prime} a$ dentro del Derecho interno. ${ }^{39}$ Fruto de los trabajos de este órgano sería la aprobación de una serie de Leyes relativas a algunos delitos ḥudūd, entre las que se encuentra una norma, del año 1973, destinada específicamente a regular el delito de fornicación ilícita, a la que más adelante nos referiremos..$^{40}$

En Mauritania, por su parte, la reorientación de su Derecho penal se produce igualmente en el contexto de un Golpe de Estado militar, perpetrado en 1978, y que derrocaría al Presidente constitucional Mujtār Ūld Dāddāh. Las nuevas autoridades militares tratarán, desde un primer momento, de atraer a los sectores más tradicionales de la sociedad, que se habían visto marginadas en el anterior régimen, al mismo tiempo que procuraban obtener la financiación y el apoyo internacional por parte de los países musulmanes más tradicionales ${ }^{41}$. En consecuencia, iniciarían una nueva política legislativa dirigida a favorecer la inserción de las disposiciones de la $\breve{S} a r{ }^{\top}{ }^{a} a$ dentro del Ordenamiento Jurídico y que culminaría con la Constitución

\footnotetext{
${ }^{39}$ Cfr. PETERS, Rudolph: "The Islamization of criminal law: a comparative analisis", Die welt des Islams, 34 (1994), p. 255.

${ }^{40}$ Libia: Qānūn raqm 70 li-sana 1973 î̀ šă'n iqāma ḥadd al-zinā wa ta'dīl ba'dú aḥām qānūn aluqū̄āt al-lībî̀̂.

${ }^{41}$ Cfr. PASTOR, Mauricio y VILLAR, Manuel (Eds.) , Las ciudades perdidas de Mauritania, Fundación El Legado Andalusí, 1996, p. 146.
} 
de 1985 en la que se establece que "la única fuente de la Ley es la Šarīa islámica" . De este modo, y en el seno de esta política, sería aprobado en 1983 un nuevo Código Penal ${ }^{43}$ que sustituía a la legislación colonial francesa, aún en vigor, y restauraba las disposiciones del Derecho musulmán de rito malikí en materia de delitos hudūd, incluyendo la cuestión de las relaciones sexuales ilícitas.

Finalmente, el caso de Sudán, el proceso de inserción de la Šarīa dentro de su legislación penal también se encuadra en un marco general de política legislativa, dirigido por el Presidente Numaīrī, quien había ascendido al poder en 1969. A lo largo de la década de los años 70 , el gobierno de Numaīrī abandonará progresivamente su discurso nacionalista y socialista para sustituirlo por otro de carácter islamista con el objetivo, por una parte de reforzar su base política interna atrayéndose a la rama sudanesa de los Hermanos Musulmanes de Hasan al-Turābī, y, por otra, de asegurar el apoyo financiero de Arabia Saudí y de Estados Unidos ${ }^{44}$. Al igual que sucedía en el caso de Libia, el gobierno de Numaīrī, en 1977 sería creado un Comité, del cual formaría parte el propio al-Turābī, y que tendría como función la de presentar propuestas para la islamización del Derecho positivo sudanés..$^{45}$ Las propuestas de este comité, junto con la determinación del Presidente Numaīrī dieron su fruto con las llamadas Leyes de Septiembre de 1983, una vasta reforma del Ordenamiento Jurídico que, entre otros aspectos, introducía un nuevo Código Penal, que penalizará todos los delitos ḥudūd conforme a las disposiciones de la Šarīa y que será la base del actual Código de 1991.

Estos nuevos textos penales van a sustituir en estos países a las anteriores legislaciones, promulgadas bien durante el periodo colonial como es el caso de Sudán y de Mauritania, o bien al poco de adquirir la independencia, como sucedió con Libia. En lo referido al delito de zinā, aquellas legislaciones, que respondían básicamente a los patrones establecidos por el Derecho francés y el anglo-sajón pasarán a ser sustituidas por una normativa inspirada en las disposiciones de la Šarī $a$, lo que provocará cambios radicales en aspectos tales como la delimitación del ámbito material del delito, los medios probatorios y el sistema de penas.

\subsubsection{El ámbito material del delito}

A pesar de estar basados en la misma tradición jurídica, los legisladores de estos países utilizan diferentes técnicas para determinar la conducta material que constituye el delito de zinā. Así, en el caso de Libia se establece una mínima descripción genérica de los elementos constitutivos del delito, esto es; la existencia de un contacto sexual -fi ${ }^{\prime}$ al-ŷima ${ }^{-}$- practicado entre un hombre y una mujer, entre

${ }^{42}$ Cfr. CENTRE D'ÉTUDE DE AFRIQUE NOIRE (Ed.): L'Afrique politique 2002. Islams d'Afrique : entre le local et le global, Karthala, París, 2003, p. 70.

${ }^{43}$ Mauritania: Ordonnance 83-162 du 09 juillet 1983 portant institution d'un Code Pénal.

${ }^{44}$ Cfr. PETERS, Rudolph: Crime and punishment in Islamic law: theory and practice from the Sixteenth to the Twenty-first Century. Cambridge. University Press, 2005, p. 164.

${ }^{45}$ Cfr. PETERS, Rudolph: "The Islamization of criminal law: a comparative analisis", Die welt des Islams, 34 (1994), p. 263. 
los cuales no exista una relación matrimonial legal ${ }^{46}$, quedando, de este modo, la apreciación de los pormenores de cada situación al criterio de los tribunales.

Por su parte, el legislador sudanés parece optar por la positivación de los criterios fundamentales establecidos por el figh para este delito, lo que se refleja tanto en la terminología como en los elementos casuísticos que son utilizadas para la determinación de la conducta delictiva. De este modo, el Código Penal sudanés establece como conducta constitutiva de zinā el hecho de que un hombre y una mujer yazcan juntos -watāi- sin que exista entre ellos un vínculo legítimo. Asimismo, el espíritu casuístico del fiqh, aparece reflejado al determinarse que esta conducta delictiva sólo se consuma cuando ha existido una completa penetración del glande o un acto equivalente ${ }^{47}$.

En el caso de Mauritania, sin embargo, el Código Penal utiliza una técnica diferente en la determinación de los elementos constitutivos del delito. Siguiendo de un modo más fiel la técnica jurisprudencial del fiqh, el legislador mauritano se limita a determinar las cuestiones relacionadas con los medios probatorios y la ejecución de la pena. Por lo tanto, estas normas serán aplicadas por los tribunales en los casos en los que consideren que existe un delito de zinā conforme a las disposiciones del fiqh malikí aplicado en aquel país. Por otra parte, el Código mauritano introduce el principio de la personalidad por razón de credo en la legislación sobre zinā, restringiendo la aplicación de las penas previstas a los casos en los que el acusado sea un musulmán, siguiendo una importante tendencia del fiqh que considera que las penas hudūd sólo resultarían aplicables a los musulmanes. Se trata de una solución que, además de adecuarse a esta concepción personal del fiqh evita, en cierta medida, importantes problemas jurídicos y políticos en los casos en los que el acusado sea extranjero.

\subsubsection{Los medios de prueba}

En lo relativo a los medios de prueba requeridos para la constatación de este delito, la legislación de estos tres países va a presentar significativas modificaciones con respecto a los medios de prueba exigidos por la $\breve{S} a r \bar{c} \mathfrak{c}$. Tal y como referimos anteriormente, uno de los ejes que configuraban el delito de zinā en la Šarīa era el equilibrio entre la gravedad de la pena y la dificultad en demostrar la existencia del delito, sobre todo en lo relativo a las condiciones de la prueba testifical. Sin embargo, tanto en el caso de Libia como en el de Sudán y Mauritania se establecen una serie de alteraciones que rompen aquel delicado equilibrio entre prueba y punición establecido por la Šar̄̄a. Se trata de unas alteraciones que, por diversas razones de política legislativa, parecen flexibilizar y, por lo tanto, facilitar en estos países la aplicación de las penas por el delito de fornicación ilícita.

${ }^{46}$ Libia: Qānūn raqm 70 li-sana 1973 fì šăn iqāma hadd al-zinā wa ta dīl ba đọ aḥām qānūn al'uqūbāt al-lībī.Art. 1.

${ }^{47}$ Sudán: Qānūn al- 'uqūbāt. Art. 145.2. 
En este sentido, el Código mauritano reproduce en su artículo 307 los medios de prueba admitidos por el fiqh malikí, esto es, el testimonio de cuatro testigos, la confesión del autor del delito y el embarazo de la mujer, en el caso de no estar casada. Sin embargo, ni en Código Penal ni el Código de Procedimiento Penal de 1983 hacen referencia alguna a las características de estos testigos, que en el Derecho clásico debían de tratarse de hombres musulmanes y poseedores de probada rectitud moral - 'adāla-. Por ello, la validez de cada testimonio habrá de ser apreciada por el tribunal juzgador caso por caso.

En el caso sudanés, sin embargo, los medios probatorios aparecen minuciosamente regulados por la Evidence Act, de 1983, una de las Leyes de Septiembre que acompañaron al Código Penal y que servían como norma adjetiva para su aplicación. Esta norma, a pesar de estar fuertemente inspirada por la doctrina procesal del Derecho islámico clásico, lo cierto es que termina por flexibilizar los rígidos requisitos que aquella establecía para la validez de la prueba testifical en los casos de zinā. En este sentido, en la Evidence Act los requisitos establecidos por la Šarīa para los testigos no son los únicos admitidos, contemplándose que el delito sea probado por otro tipo de testigos a discreción del Tribunal, lo que, en la práctica abre el camino para el testimonio de mujeres ${ }^{48}$. Asimismo, la Evidence Act, siguiendo la Escuela malikí, admite la prueba circunstancial del delito de zinā en el caso del embarazo de la mujer no casada. ${ }^{49}$

Finalmente, en Libia la separación del sistema probatorio de la Šarīa se presentaría de un modo más acusado ya que se establece, con carácter general, que la doctrina de las Escuelas Jurídicas islámicas será la fuente subsidiaria para las cuestiones no previstas en aquella norma, pero, seguidamente, se incluye una precisión según la cual las cuestiones procesales de este delito serán reguladas por el Código de Procedimiento Penal, lo que abarca, claro es, la cuestión de los medios probatorios $^{50}$. Esta remisión suponía que el régimen probatorio del delito de zinā quedaba equiparado al de los demás delitos, sobrepasándose ampliamente el restrictivo campo establecido por la $\breve{S} a r{ }^{`} a$. Sin embargo, en 1998 se aprobaría una enmienda a esta ley según la cual los medios de prueba del delito de zinā quedarían restringidos a los establecidos por la $\breve{S} a r \bar{\imath}$ a, es decir el reconocimiento del acusado o el testimonio de cuatro testigos, a los cuales se añadiría "cualquier otro medio científico de prueba". ${ }^{\text {s1 }}$

\subsubsection{Las penas}

En lo que se refiere a las penas previstas ante este delito, a pesar de partir en los tres casos del sistema establecido por la $\breve{S} a \bar{r}^{\complement} \mathfrak{a}$ a se aprecian importantes diferencias en lo que se refiere a su naturaleza y a su extensión.

\footnotetext{
${ }^{48}$ Sudán: Evidence Act, 1983, arts. 77 y 78.

${ }^{49}$ Id. Art. 77.

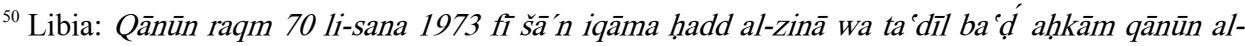
'uqūbāt al-lībī Art. 10.

${ }^{51}$ Id. Art. 6.
} 
Por una parte, estas diferencias se derivan de la aplicación del principio de la personalidad. De este modo, si en Mauritania los no musulmanes quedaban fuera de este tipo delictivo, en Sudán, los habitantes de las Provincias del Sur, mayoritariamente de religión cristiana y animista del sur quedan exentos de los castigos físicos establecidos para este delito cuando es cometido en el resto del país, y en su lugar son sancionados con una pena de prisión, agravada en el caso de que el condenado esté casado ${ }^{52}$, mientras que la legislación de Libia no prevé ninguna excepción de carácter personal a la aplicación de la pena.

Por otra parte, existe otra importante diferencia en lo que se refiere a la extensión de la pena entre estos tres países. Por un lado, salvando las excepciones personales antes referidas, para los casos de relaciones sexuales entre individuos no casados, se determina, en los tres casos, una sanción penal consistente en la flagelación del delincuente con cien latigazos, de acuerdo a la pena hadd establecida por la $\breve{S} a \bar{r}^{e} a^{53}$, a lo que se suma un año de prisión, proveniente de la pena de destierro que algunas Escuelas, como la malikí, establecían en estos casos.

El objetivo de la flagelación es el de infringir dolor pero no el de provocar el fallecimiento del condenado. De este modo, en el caso mauritano, el procedimiento de aplicación de esta pena contempla algunas previsiones, derivadas de la detallada casuística del fiqh malikí, sobre esta cuestión ${ }^{54}$. De este modo, si el culpable está enfermo, la ejecución de la pena se suspenderá hasta su restablecimiento, y si se tratara de una mujer embarazada la flagelación se suspenderá hasta después del parto. ${ }^{55}$ Por su parte, la legislación libia establece una serie de previsiones más técnicas para la ejecución de la flagelación que tienen igualmente por objetivo preservar la vida del condenado, tales como la ejecución de la pena en presencia de un Fiscal y de un médico o la interrupción de la pena en el caso de que el médico considere existir peligro de muerte de dicho condenado. ${ }^{56}$ Igualmente en Sudán, a pesar de no estar explícitamente previsto en el Código Penal, la ejecución de las penas de flagelación se realiza en presencia de un médico. ${ }^{57}$

Ahora bien, junto a esta sanción, en los Códigos de Sudán y de Mauritania existe un tipo penal agravado del delito de zinā. Este tipo se refiere a las relaciones sexuales mantenidas entre individuos que no son solteros, en cuyo caso la condena establecida es la muerte por lapidación.

Esta es una adaptación en la legislación positiva de las prescripciones del fiqh que determinaban esta pena para los culpables de zinā que tuvieran el estatuto legal de muhhșan, es decir que se tratara de individuos adultos, libres, musulmanes, excepto

${ }^{52}$ Sudán: Qānūn al- 'uqūbāt. Art 146.4.

${ }^{53}$ Corán, 24,2.

${ }^{54}$ Vid. MĀLIK, Ibn Anās, Muwatțā', 41.1.5 y ss.

${ }_{55}^{55}$ Mauritania: Ordonnance 83-162 du 09 juillet 1983 portant institution d'un Code Pénal. Art. 307.

${ }^{56}$ Libia: Qānūn raqm 70 li-sana 1973 fì šā'n iqāma hadd al-zinā wa ta dîl ba 'ứ aḥām qānūn al¿uqūbāt al-lī̄īi . Art. 7.2.

${ }^{57}$ PETERS, Rudolph: Crime and punishment in Islamic law: theory and practice from the Sixteenth to the Twenty-first Century. Cambridge. University Press, Cambridge, 2005, p. 167. 
para la escuela shafi'í que también incluye a los no musulmanes, ${ }^{58}$ y que hubieran tenido previamente relaciones sexuales legítimas en el seno de un matrimonio.

Ahora bien, la categoría de muhșan es interpretada de modo diferente en ambos Códigos. Así, el Código mauritano realiza una interpretación extensiva de este concepto, determinando la pena de muerte por lapidación tanto para los culpables de zinā que estén casados como para los divorciados. ${ }^{59}$ Por su parte, esta misma interpretación parecía desprenderse del Código penal sudanés de 1983; sin embargo, tras una serie de pronunciamientos del Tribunal Supremo de este país, el ámbito de esta categoría ha quedado restringido, al considerar que las personas divorciadas no debían ser consideradas como muhșan a efectos de la pena por zina $\widehat{a}^{0}$. En consecuencia con esta interpretación, el nuevo Código sudanés de 1991 estableció una nueva definición del ihṣān, consistente en "la existencia de un matrimonio válido en el momento de la comisión del adulterio y siempre que haya sido consumado a través de la penetración'st.

Por su parte, el legislador libio adoptó un camino peculiar sobre esta cuestión ya que no reconoce esta sanción en ningún supuesto, estableciendo apenas la posibilidad de combinar la pena de flagelación con una pena de prisión a determinar por el juez ${ }^{62}$, lo que permite su aplicar una sanción cualificada a los casos de adulterio. Se trata, sin duda, de una interpretación exclusiva de la Šarī́a, fundada en el propio texto coránico ${ }^{63}$, en el que apenas se menciona la pena de flagelación, como se vio anteriormente, pero que prescinde del resto de la doctrina jurídica

De hecho, la legislación libia sobre el delito de zinā determina que la pena de flagelación establecida en aquel texto tiene el carácter de pena hadd y que, en consecuencia, no puede ser alterada, sustituida, alterada o perdonada; sin embargo, tal y como señala MAYER ${ }^{64}$, esta previsión se refiere a las penas ḥudūd que están establecidas en aquel texto y no a la $\breve{S} a r{ }^{\top}$ a. Por lo tanto, esta previsión garantiza a sensu contrario que penas, tales como la de lapidación, no podrán ser establecidas por los jueces ante los casos de zinā. Junto a la presumible falta de voluntad política del gobierno libio de imponer una sanción tan severa e tan impopular en la escena internacional, MAYER señala otra interesante hipótesis para justificar este desvío. En su opinión esta opción estaría relacionada con el discurso político de Qaddāifi, en lo que respecta al retorno del Corán como fuente primaria del Derecho Positivo. ${ }^{65}$ En este sentido, el modelo libio de legislación sobre el delito que nos ocupa, podría ser considerado como una tercera vía para el encuadramiento de la Šarī'a dentro de la legislación penal contemporánea.

${ }^{58}$ Ibid., p. 61.

${ }^{59}$ En este sentido se pronuncia el Art. 307 del Código mauritano en su versión francesa, que es la que hemos utilizado en este trabajo.

${ }^{60}$ Cfr. SIDAHMED, Abdel Salam: "Problems in contemporany applications of Islamic criminal sanctions: the penalty for adultery in relation to women", British Journal of Midle Eastern Studies, 28, 2 (2001), p. 201-203.

${ }^{61}$ Sudán: Qānūn al- ‘uqūbāt. Art 146.3. (Original en árabe, la traducción es nuestra).

${ }^{62}$ Pena que, en aplicación del Art. 407 del Código Penal libio, puede alcanzar hasta los 5 años de prisión.

${ }^{63}$ Corán 24, 2.

${ }^{64}$ Cfr. MAYER, Ann Elizabeth: "Libyan legislation in Defense of Arabo-Islamic Sexual Mores", The American Journal of Comparative Law, 28, (1980), p. 299.

${ }^{65}$ MAYER, Ann Elizabeth, (Op. Cit.), p. 297-298. 


\subsection{LA CONTINUIDAD EN EL DERECHO ISLÁMICO CLÁSICO}

Los sistemas jurídicos en los que la regulación del delito de zinā se configura alrededor de las prescripciones de la $\breve{S} a r{ }^{\top}{ }^{`} a$ no se corresponden en todos los casos al abandono de una legislación de carácter occidental heredada del periodo colonial o adoptada tras su independencia. De hecho, existen algunos países, situados en la Península Arábiga, que han mantenido una continuidad en su legislación penal, en torno a un modelo de Derecho Penal inspirado en las disposiciones de la Ley Islámica, en la materia que nos ocupa. Estos son los casos de Arabia Saudí, Qatar, los Emiratos Árabes Unidos y Yemen, De este modo, a pesar de que en los aspectos procesales estos países han modernizado su derecho adoptando instituciones jurídicas occidentales, la ley sustantiva que aplican, especialmente en lo que se refiere a los delitos hudūd, como el de zin̄ā, se basa en la doctrina de las Escuelas Jurídicas clásicas.

Quizá el modelo más representativo de este sistema jurídico sea el de Arabia Saudí. Al contrario que en otros países, en los que la aplicación de la Šarīa ha sido regulada por el Estado a través de la codificación de las leyes penales, como es el caso de Sudán o Yemen, o bien a través del establecimiento de límites a su aplicación, como sucede en Libia, en el Reino Saudí el Estado no ha interferido a través de la legislación en la aplicación jurisprudencial de la Ley Islámica. De hecho, esta continuidad en la aplicación de la $\breve{S a r i ̄ a ~ a p a r e c e ~ r e c o n o c i d a ~ e n ~ e l ~ a r t . ~} 48$ de la Ley Fundamental del Reino cuando establece que: "Los tribunales aplicarán, en los casos de su competencia, las reglas de la Šarīa islámica de acuerdo con las prescripciones del Libro o de la Sunna y la regulación establecida por el legislador que no contradiga el Libro o la Sunna". ${ }_{66}$

Esta disposición de la Ley Fundamental saudí supone que los casos que impliquen delitos hudūud como el de zinā, serán resueltos por los tribunales aplicando el Derecho secular de las Escuelas Jurídicas clásicas. No existe ninguna norma que determine la Escuela que debe ser seguida aunque, de modo predominante, los tribunales saudíes utilizan la doctrina de la Escuela Hanbalí.

En consecuencia, las prescripciones del fiqh, en lo que se refiere al ámbito material del delito, a los medios de prueba y a las sanciones previstas, responden fielmente al equilibrio que la Šarı̄ a establece entre la severidad de la sanción y los medios de prueba cualificados que pueden ser admitidos para demostrar judicialmente la existencia del delito. Efectivamente, la exigencia de la prueba testifical por cuatro testigos visuales del acto, o bien la necesidad de autoconfesión provocan que, en la práctica, sea poco habitual la aplicación de las penas hudūd por este delito ${ }^{67}$. En este sentido, son habitualmente admitidos como exculpatorios, ante la prueba circunstancial del embarazo de mujeres solteras, argumentos tales como la previa violación o la fecundación producida mientras la acusada estaba durmiendo. ${ }^{68}$ Sin embargo, en el caso

${ }^{66}$ Cfr. PETERS, Rudolph, (2005), Op. Cit., p. 149.

${ }^{67}$ En este sentido VOGEL recoge un estudio estadístico que muestra que en el periodo comprendido entre 1981 y 1992 apenas fueron ejecutadas cuatro penas de muerte por lapidación ante delitos de zinâ. Cfr. VOGEL, Frank : Islamic Law and Legal System : Studies of Saudi Arabia, Brill, Leiden, 2000, p. 370.

${ }^{68}$ SIDAHMED, Abdel Salam: "Problems in contemporany applications of Islamic criminal sanctions: the penalty for adultery in relation to women", British Journal of Midle Eastern Studies, 28, 2 (2001), p. 193. 
de no haber sido verificados todos los estrictos requisitos probatorios para la pena hadd, el tribunal siempre podrá imponer una pena en virtud del ta'zirir, es decir, la potestad discrecional sancionadora del juez en la Šar̄̄a que será una pena de prisión e incluso de flagelación, siempre inferior a la pena hadd de los cien latigazos.

Igualmente, las garantías procesales en el caso de estar en causa la aplicación de la pena de muerte son reforzadas con la exigencia de que la sentencia en Primera Instancia sea pronunciada por un colectivo de tres magistrados, así como por la necesidad de apelar este fallo ante el Tribunal de Apelación y, en el caso de ser confirmada, ante el Consejo Judicial Supremo. Finalmente el Rey deberá revisar la sentencia final antes de ordenar la ejecución ${ }^{69}$.

A diferencia de Arabia Saudí, el Emirato de Qatar ha vivido durante una gran parte del siglo XX y hasta la su independencia en 1971 en un cuadro de pluralismo legislativo, basado en el principio de la personalidad del derecho. Al igual que sucedió con otros Estados ribereños del Golfo Pérsico, Qatar quedaría situado bajo la esfera de influencia de Gran Bretaña, constituyéndose como Protectorado británico en 1916.En virtud de este estatuto jurídico Gran Bretaña establecería una jurisdicción propia en el Emirato con competencias penales en causas en las que estuvieran implicados nacionales británicos o de otros Estados de la Commonwealth y que ejercía sus funciones aplicando las leyes británicas. Esta jurisdicción coexistiría con otra, ejercida por las autoridades locales, sobre la base de la $\breve{S a r T ̄ a}$ islámica, y que tendría competencia en las causas sobre ciudadanos de Qatar, y de otros países árabes y musulmanes, con excepción de los pertenecientes a la Commonwealth.

La obtención de la independencia del Emirato, en 1971, provocaría el cese de la jurisdicción británica y plantearía nuevamente la cuestión de qué técnica seguir para establecer la jurisdicción penal del Estado sobre una población que contaba ya con una presencia permanente de extranjeros no musulmanes, establecida a partir del desarrollo de la industria petrolífera. Al contrario que en otros países en los que se estableció un monismo legislativo basado en modelos occidentales, la solución seguida por el legislador qatarí consistió en mantener el dualismo legislativo, con el establecimiento de una Corte de Justicia (maḥkama al-'adliyya) , que sería competente en causas penales que implicaran a ciudadanos no musulmanes, y el mantenimiento de los tribunales basados en la $\breve{S} a r{ }^{`} a$, con competencia en causas abiertas contra musulmanes, tanto qataríes como extranjeros. ${ }^{70}$

Esta situación jurídica aparece plasmada en el artículo 1 del Código penal qatarí, en el que, se establece que: "Se aplicarán las prescripciones de la Šarīa islámica en las siguientes materias penales, siempre que el acusado o la víctima sean musulmanes: 1. Los delitos hudūd relativos al robo, la fornicación ilícita y su falsa acusación, el consumo de vino y la apostasía".?1

Como consecuencia de esta remisión, los delitos de zinā cometidos por musulmanes son juzgados por los tribunales de la Šarīa conforme a las

${ }^{69}$ VOGEL, Frank, (Op.Cit.), p. 246.

${ }^{70}$ Cfr. HAMZEH, A. NIZAR: « Qatar: The Duality of the Legal System », Middle Eastern Studies, 30, 1, (1994), p. 81-83.

${ }^{71}$ Qatar: Qānūn al- 'uqūbāt. Art 1. (Original en árabe, la traducción es nuestra). 
prescripciones del Derecho Islámico, preferentemente de la Escuela Hanbalí. El ámbito material de delito, el sistema de pruebas y las penas responden, por lo tanto a esquemas semejantes a los de Arabia Saudí. Así, el sistema procesal es marcadamente "garantista" y las penas de muerte sólo pueden ser ejecutadas tras la ratificación del Emir, que se reserva la potestad de conmutarlas.

Igualmente, en los Emiratos Árabes Unidos, la cuestión del delito de zināan, así como los delitos hudūd, en general se ha mantenido fuera de la codificación penal aunque por diferentes motivos. Históricamente, hasta su constitución como Federación en 1971, los territorios que componen este Estado habían mantenido una plena autonomía jurídica con competencias legislativas en materia civil y penal y con sistemas judiciales propios, basado en las disposiciones de la Sarīa. Sin embargo, la jurisprudencia de estos tribunales variará considerablemente conforme a las Escuelas jurídicas a las que se adherirán en su doctrina. De este modo, mientras que los Emiratos de Abu Dhabi y de Dubai se regirán por el rito malikí, en el resto predominará la Escuela Hanbalí. Por ello, tras la aprobación de la Constitución de 1971 y el establecimiento de órganos jurisdiccionales comunes, como la Corte Suprema, la unificación de las legislaciones de los Emiratos se convertiría en un objetivo estratégico del Gobierno federal. Este hecho, junto con el interés que originaría el proceso de islamización del ordenamiento jurídico desarrollado en otros países musulmanes como Libia, Irán o Pakistán ${ }^{72}$, llevaría al Gobierno Federal a promover un proceso de modernización de su Derecho Penal que tuviera como ejes la codificación y la unificación de la jurisprudencia que había sido tradicionalmente aplicada ante materias reguladas por la Šar̄̄a. Para ello, en 1978, sería nombrada una Comisión con las funciones de identificar aquellas cuestiones en las que el ordenamiento jurídico entraba en conflicto con la $\breve{S} a r \bar{a} a$, y de proponer nuevas normas que eliminaran dichos conflictos. De hecho, la influencia del proceso de reislamización adoptado en Libia se refleja en la composición de la Comisión designada para este cometido por el Gobierno de los Emiratos. Esta Comisión sería presidida precisamente por el mismo jurista que años atrás había desempeñado el mismo cometido en el país norteafricano.

En lo que se refiere al Derecho Penal, la función de este Comité sería la de identificar la jurisprudencia aplicable a las categorías fundamentales de delitos de la Šarī́a y transformarla en artículos compilados en Códigos bajo una estructura propia del Derecho Occidental. Como resultado de los trabajos de este Comité, en 1987 sería redactado un Proyecto de Código Penal para su apreciación por parte del Gobierno. En dicho texto el delito de zinā será presentado bajo una forma ecléctica, intentado presentar una postura aceptable por los Tribunales de los distintos Emiratos. Así, por ejemplo, en lo que respecta al ámbito material del delito utilizaría un criterio extensivo que incluía la sodomía entre las formas de zinā (art. 484), siguiendo las prescripciones de las Escuelas Malikí, Shafi'i y Hanbalí. Sin embargo en otros aspectos, como la prescripción de la pena para el autor del delito

${ }^{72}$ MUHAIRI, Butti Al-, "The Islamization of Laws in the UAE: The Case of the Penal Code", Arab Law Quarterly, 11, 4 (1996), p. 352-353 
cuando no está casado, se aplicará el criterio establecido por la Escuela Hanifí, que la limita a cien latigazos (art. 485), sin incluir pena de prisión ni de destierro como sucedía en las otras Escuelas. Sin embargo, durante su revisión, el Gobierno optaría por suprimir los artículos referidos a los crímenes hudūd, incluyendo en el Art. 1 del Código Penal una remisión a la aplicación judicial de la Šar̄̄a para este tipo de cuestiones, siguiendo la técnica del Código qatarí.

A falta de una explicación oficial para este cambio de orientación, la doctrina ha barajado distintas hipótesis. AL-MUHAIRI interpreta que con el objeto de evitar las críticas internacionales a un texto penal que prescribía los castigos físicos ante ciertos delitos, el Gobierno optó por mantener en un plano más discreto esta cuestión, relegándola a su aplicación por parte de los Tribunales ${ }^{73}$. Sin embargo el propósito de la unificación penal no queda del todo eliminado ya que el Código Penal mantiene la mayoría de las penas ta $z \bar{I} r$ propuestas por la Comisión. Sin embargo, el Código no establece una pena ta'zīr específica para los delitos de zinā. Ello ha dado lugar a una jurisprudencia vacilante en los Tribunales de Apelación en los casos en los que el delito de zinā no puede ser sancionado con la pena hadd. Esta jurisprudencia ha oscilado durante los últimos años, entre la aplicación de la sanción de prisión establecida en el Art. 356 del Código y que se refiere al delito de "indecencia" consentida, y la aplicación de la pena de flagelación, en un número inferior de latigazos al previsto para la pena hadd, conforme prescribe la $\breve{S} a r{ }^{\complement}{ }^{\complement}{ }^{74}$ Se trata de una jurisprudencia que, en el fondo, manifiesta una compleja discusión doctrinal, como es la de la aplicación de la penas ta'zír en los casos que apenas refiere el Código, conforme al principio de legalidad reconocido en la Constitución, o bien la del permitir su aplicación discrecional por parte de los Tribunales en cuanto principio inherente a la $\breve{S} a r \bar{c}$ a . Probablemente se trate de una cuestión en la que será difícil establecer una doctrina unánime, debido a la compleja estructura federal de los Tribunales en los Emiratos Árabes Unidos y a la falta de unidad de criterios entre el Gobierno, más interesado en la unificación legislativa, y los Tribunales superiores, más interesados en mantener su tradicional autonomía jurisdiccional.

En el caso de Yemen, la implantación del Derecho Islámico como base de su regulación penal, hunde sus raíces en el conturbado proceso que condujo a la constitución de la actual República de Yemen, en 1990.

En este sentido, la diferente orientación política que adoptarán las dos Repúblicas yemeníes durante el periodo de división, va a incidir directamente en la orientación de su Derecho Penal. Por una parte, la República Árabe de Yemen, establecida en el Norte del país desde 1962, tras la deposición del antiguo Imanato, va a mantener, en gran medida, intacto el sistema de justicia penal heredado del Régimen anterior. Esta orientación responde a diversos factores entre los que se puede destacar el propio aislamiento de una región, montañosa y de difíciles comunicaciones con el exterior, así como su juego de alianzas internacionales en su

\footnotetext{
${ }^{73}$ Cfr. MUHAIRI, Butti Al-, (1996), Op. Cit. p. 369 y ss.

${ }^{74}$ Cfr. MUHAIRI, Butti al-: "The incompatibility of the Penal Code with Shari a", Arab Law Quarterly, 12, 3 (1997), p. 314 y ss.
} 
enfrentamiento con el Sur, que le llevaría a valerse del apoyo de Arabia Saudí y de Estados Unidos. En consecuencia, la legislación penal se mantendrá sin codificar y materias tales como el delito de zinā, y los delitos hudūd en general, serán resueltas por los Tribunales locales mediante la aplicación de la Šarị a islámica.

Por su parte, en la zona sur del país, sobre la que en 1967 sería declarada la República Popular Democrática del Yemen se partía de una tradición jurídica diferente. Este territorio, y especialmente la zona de Adén, fue tradicionalmente una región de influencia de Gran Bretaña por su condición de escala en su ruta hacia la India. Como consecuencia de ello, el Sur de Yemen tendrá una tradición de Derecho Penal codificado y de influencia occidental que se extenderá desde que, en 1937, le fuera otorgado el Código Penal anglo-indio. Tras la retirada británica y la constitución de la República Popular Democrática, el nuevo Estado adoptaría una ideología oficial de carácter socialista que se reflejará en su legislación. Así, en 1976 sería promulgado un Código Penal marcado por la influencia por el Derecho Penal soviético.

Fruto de esta influencia, el Código Penal del Yemen del Sur no establecerá ninguna sanción para las relaciones sexuales extramatrimoniales, ya fueran adúlteras o no. De hecho este Código se limita a sancionar en su Art. 167 las relaciones sexuales con menores de 16 años con una pena de 3 años de prisión, lo que responde a una lógica diferente del delito de zinā establecido en los demás países árabes. De este modo, esta República se convertía en el primer Estado árabe que se sumaba a la corriente internacional de países que establecían la despenalización de las relaciones sexuales consentidas entre adultos, independientemente de su Estado Civil; una corriente representada inicialmente por los países socialistas y por los escandinavos y hoy día en clara expansión. ${ }^{75}$

Sin embargo, tras la reunificación del país en 1990 se procedería a la implantación de un sistema jurídico único para todo el país que acabaría con aquella experiencia pionera abolicionista. Factores tales como el establecimiento de un sistema democrático en una situación de desequilibrio demográfico a favor del Norte, favorecerían la progresiva implantación de la legislación de aquel territorio en todo el país, lo que contribuiría a desencadenar a una breve guerra civil, en mayo de 1994, que acabaría con la derrota del Sur.

Tras esta derrota, los modelos legislativos seguidos en el Norte se impondrían claramente en la legislación del Yemen unificado. Esto se verificaría, por ejemplo, en el nuevo Código Penal de 1994. Se trataba de un texto que, siguiendo la tradición jurídica del Norte, va a resolver una serie de materias penales, como son los delitos h̆udūd conforme a las disposiciones de la Šar ${ }^{\top} a$. Sin embargo, y teniendo en cuenta que en el Sur no existían, desde hacía décadas, jueces ni Tribunales especializados en la aplicación de la ley penal islámica, en lugar de realizarse una remisión a este derecho jurisprudencial desde un nivel constitucional como en Arabia Saudí, o legislativo como en Qatar, el legislador yemení hubo de procederse a una codificación o "positivación" este derecho dentro de una serie de capítulos entre los que se incluye

${ }^{75}$ Sobre esta cuestión Vid. HADJIYANNAKIS, Constantin: Les tendances contemporaines concernent la répression du délit d'adultère, Georgiades, Salónica, 1969, p. 116 y ss. 
uno dedicado al delito de zinā. Este propósito del legislador se refleja, de un modo general, en las numerosas condiciones que el Código Yemení establece tanto para la prueba del delito como para la imposición y ejecución de la pena, condiciones que tratan de refleja la rica casuística establecida por el fiqh sobre esta cuestión.

En lo que se refiere al ámbito material del delito, el Código Yemení determina un tipo delictivo extensivo que incluye toda relación sexual consumada entre personas que no estén vinculadas por un matrimonio válido y siempre que no exista coacción o exista una apariencia de legalidad en su relación que cree una duda razonable (̌̌ubha) sobre la conducta delictiva ${ }^{76}$. Ahora bien, a diferencia de otros Códigos como el sudanés o el mauritano que individualizan esta conducta penal, el Código yemení, siguiendo la doctrina de la Escuela shafi 'i ${ }^{\prime \prime}$ sobre esta cuestión, incluirá la sodomía (al-liwăt) como una variedad de zinā, independientemente de que el sujeto pasivo sea una mujer o un hombre, es decir un contacto homosexual ${ }^{78}$.

La consecuencia de este criterio es que, por el hecho de la penetración, los actos homosexuales masculinos quedan equiparados en el tratamiento penal a los heterosexuales. Sin embargo, las relaciones sexuales femeninas (al-sịhāq), a pesar de aparecer en el Código yemení incluidas dentro de la categoría de actos constitutivos de zinā, tienen un tratamiento penal diferenciado de los anteriores. En este caso, y siguiendo nuevamente la doctrina del fiqh, las relaciones sexuales entre mujeres quedan excluidas de la pena haddy, en su lugar, son sancionadas exclusivamente con pena de prisión de hasta tres años que se elevarán a siete en el caso de existir coacción. ${ }^{79}$

La sanción penal establecida para los anteriores casos responde plenamente a las disposiciones del fiqh, es decir, la de cien latigazos en el caso de que el acusado no tenga la condición de muhssan y la pena de muerte por lapidación en el caso contrario. Por ello, dada la trascendencia de esta circunstancia, a efectos de imposición de la pena, se establecen una serie de condiciones para el reconocimiento del ihṣān, como son las de haber consumado un contacto sexual con su cónyuge, de mutuo acuerdo y dentro de un matrimonio legal, que este cónyuge sea una persona en pleno uso de razón y que se trate de una relación matrimonial continuada. Estos criterios, adoptados igualmente del fiqh, suponen la atribución de este elemento cualificador tanto a personas casadas como a las divorciadas y viudas.

Sin embargo, estos criterios extensivos aparecen en la práctica condicionados por una larga lista de circunstancias que de modo individual son capaces de impedir la aplicación de la pena hadd. Es quizá en este aspecto en donde mejor se refleja la influencia de la casuística del fiqh. Así, junto a situaciones de carácter procesal como son, la existencia de contradicciones entre los testigos, o bien el que al menos uno de ellos se retracte de su testimonio, la retirada de la autoinculpación por parte del procesado cuando es la única prueba, o la alegación por el acusado de la existencia de coacción (al-Ikräh) o necesidad (al-ḍarūra), se incluyen elementos circunstanciales como son, la declaración por parte de mujeres de que la acusada de zināes virgen, o la

\footnotetext{
${ }^{76}$ Yemen: Qānūn al-ŷarā'im wa-l- 'uqūbāt. Art. 263.

${ }^{77}$ PETERS, "Zinâ or Zinâ' ”, Encyclopeadia of Islam, Second Edition. Brill, Leiden, 2005, p. 551-552.

${ }^{78}$ Yemen: Qānūn al-ŷarā'im wa-l- 'uqūbāt. Art. 264.

${ }^{79}$ Id. Art. 268.
} 
mudez sobrevenida del acusado antes de su declaración, en los casos de autoinculpación, o del testimonio de los testigos, ya que impediría el derecho a la defensa. ${ }^{80}$

La ausencia de alguno de los requisitos mencionados así como la consideración por parte del Tribunal de alguna de aquellas circunstancias eximentes abre la puerta del ta ${ }^{2} \bar{i}$, que el Código yemení limita a una pena de hasta tres años de prisión. ${ }^{81}$

De este modo, el Derecho Penal yemení reconoce los pilares básicos de la doctrina clásica sobre el delito de zinā, es decir, la previsión de unas sanciones muy severas que están sometidas a unas estrictas condiciones procesales que en la práctica dificultan en gran medida su aplicación, lo que abre la puerta a un sistema de sanciones, que en este caso resulta más acorde con los sistemas de Derecho Penal contemporáneo, es decir, una pena de prisión, cuyo plazo máximo aparece establecido previamente en una norma, conforme al principio de legalidad, y que sustituye la discrecionalidad judicial del ta $z \bar{r}$.

\section{CONCLUSIONES}

El examen comparado de la legislación penal en materia de relaciones sexuales ilícitas nos muestra profundas entre los países árabes. Así, mientras que en algunos países esta conducta penal puede acarrear una reducida pena de prisión, o incluso una simple multa, en otros países puede ser sancionada con la pena de muerte. Estas divergencias son difícilmente achacables a un mayor o menor aperturismo de la mentalidad de las sociedades árabes ante esta cuestión. De hecho, su razón de ser parece situarse en un contexto más general como es el de la formación y evolución del Derecho Penal en estos países. Estos Derechos Penales encuentran sus orígenes básicamente en dos fuentes; por una parte el Derecho Penal de las potencias europeas que colonizaron aquellos países, principalmente de Francia, y por otra la $\breve{S a r i ̄ a}$, tal y como había sido interpretada por las Escuelas Jurídicas clásicas.

En la mayoría de los casos, la legislación sobre este delito no responde a un progreso continuado del ordenamiento jurídico de acuerdo a las situaciones sociales sino que se integra en un contexto de importantes cambios políticos, como es la salida del poder colonial, Golpes de Estado o guerras civiles, que son seguidos por una nueva política legislativa en la que se integraría la regulación de este delito.

Uno de los objetivos perseguidos por estas políticas legislativas ha sido el de sustituir el pluralismo jurídico propio del periodo colonial por una legislación penal moderna de carácter territorial. Esta extensión de la soberanía del Estado a las numerosas comunidades no musulmanas, asentadas en los países árabes antes y durante el periodo colonial, planteaba numerosos problemas políticos y jurídicos debido a la fundamentación religiosa y jurisprudencial del Derecho sobre el delito de relaciones sexuales ilícitas aplicado en la mayoría de los países árabes.

Ante esta situación, los legisladores de estos países han respondido de manera diferente. Por una parte un grupo de países ha optado por sustituir la legislación

\footnotetext{
${ }^{80}$ Id. Art. 266.

${ }^{81}$ Id. Art. 267.
} 
islámica clásica de la zinā por la legislación europea en materia de adulterio. Se trata de una solución que, además de superar los problemas de personalidad antes mencionados, situaba la legislación sobre este delito dentro del proceso de modernización que suponía la codificación del Derecho Penal y el establecimiento del Principio de Legalidad en los nuevos Estados árabes independientes.

Sin embargo, a partir de la década de los años 70 se aprecia como un conjunto de países árabes sustituirán esta legislación de corte occidental por otra inspirada en las prescripciones de la Šarı̄ a. Esta reintroducción del Derecho penal islámico se realizará en contextos políticos especialmente conturbados en los que la política legislativa será un factor dentro del juego de las alianzas internas entre facciones rivales.

Esta reintroducción se realizará a través de la promulgación de nuevas leyes penales que suponen en la práctica la creación de algo nuevo, una forma de derecho penal basada en las reglas sustantivas de la $\breve{S} a r{ }^{\prime}{ }^{\prime} a$ codificadas y encuadradas dentro de una ley adjetiva de tipo occidental, con tribunales e instituciones inspirados en modelos europeos. Se abandona, por tanto, el sistema jurisprudencial del fiqh y se "positiviza" el Derecho Penal con el fin de que pudiera ser aplicado por Tribunales civiles, habituados a la ley codificada de tipo europeo y sin experiencia en el ámbito del fiqh.

Finalmente, en el área de la Península Arábiga, algunos países, tras su acceso a la independencia, han optado por mantener una continuidad jurídica, aplicando, de modo más o menos integral, las disposiciones de la $\breve{S} a r \bar{r}$ a como fuente jurídica para regular la cuestión de las relaciones sexuales ilícitas. El paradigma de este sistema ha sido y es Arabia Saudí, cuyo modelo jurídico ha sido una referencia para otros países como Qatar o Emiratos Árabes Unidos, que en cierta medida, regulan la cuestión de las relaciones sexuales ilícitas a partir del sistema jurisprudencial del Derecho Islámico, manteniéndola, por lo tanto, fuera de sus Códigos Penales. 